\title{
Qualidade do leite de propriedades familiares praticantes de integração lavoura-pecuária em função do uso do solo
}

\author{
[Milk quality of family farms practicing crop-livestock integration depending on land use] \\ D.B. Santos ${ }^{1}$, J. Vanin ${ }^{1}$, C.G. Silva ${ }^{2}$, C. Bondan ${ }^{2}$, E.C. Bortoluzzi ${ }^{2}$ \\ ${ }^{1}$ Alunas de pós-graduação - Universidade de Passo Fundo - Passo Fundo, RS \\ ${ }^{2}$ Faculdade de Agronomia e Medicina Veterinária - Universidade de Passo Fundo - Passo Fundo, RS
}

\begin{abstract}
RESUMO
O objetivo do estudo foi investigar o uso do solo em propriedades familiares (PF) manejadas sob integração lavoura-pecuária (ILP) em bacia hidrográfica e relacionar com a qualidade do leite. Para tal, 14 $\mathrm{PF}$ foram caracterizadas e agrupadas quanto ao uso do solo (Grupos 1, 2 e 3) e monitoradas quanto à qualidade do leite, durante os meses de maio de 2010 a fevereiro de 2011. Nas amostras de leite, avaliouse o teor de gordura, proteína e sólidos não gordurosos. Observou-se que o uso do solo objetivando o cultivo de grãos em detrimento do pastejo animal influencia negativamente o teor de gordura e proteína, em média $6,3 \%$ e 5,4\%, respectivamente, sobretudo no período de verão. Assim, o planejamento de uso do solo em PF manejadas sob ILP é fundamental, pois a competição entre as atividades reflete na qualidade do leite. As PF especializadas na atividade leiteira apresentam melhor qualidade do leite durante as estações do ano.
\end{abstract}

Palavras-chaves: planejamento, bacia hidrográfica, qualidade do leite

\begin{abstract}
The aim of this study was to investigate the land use practiced on family farms (FF), managed under crop-livestock integration (CLP) in the watershed and to evaluate the quality of milk. 14 FFs were characterized and grouped regarding soil use (Group 1,2 and 3) and the quality of milk was monitored during the months of May, 2010 to February 2011. In these milk samples, we evaluated the fat, protein and non-fat solids content. It can be observed that the use of soil in a crop-livestock integration system, when the grain cultivation is prioritized over the animal grazing, influences negatively the fat and protein content, on average $6.3 \%$ and $5.4 \%$, respectively, especially during the summer. Thus, the planning of the use of soil in FF managed under CLP is essential, because the competition between the activities was reflected in the quality of milk. The FF specialized in dairy farming produces better quality milk in all annual seasons.
\end{abstract}

Keywords: planning, watershed, quality of milk

\section{INTRODUÇÃO}

O estado do Rio Grande do Sul é o segundo maior produtor de leite no Brasil, com produção anual superior a 3,4 bilhões de litros, dos quais a maioria é produzida em estabelecimentos caracterizados como de agricultura familiar (Martins et al., 2006; Brasil, 2009). Nesses estabelecimentos, a restrição em superfície para a realização das atividades agropecuárias levou à adoção de sistemas intensivos e integrados de produção (Carvalho et al., 2005; Anghinoni et al., 2011), os quais, por vezes, aumentam as pressões antrópicas sobre áreas frágeis (Albuquerque et al., 2011).

Em especial na região norte do Rio Grande do Sul, a integração entre lavoura e pecuária (ILP), sobretudo a pecuária leiteira, vem sendo

Recebido em 21 de maio de 2012

Aceito em 9 de abril de 2013

E-mail: agro_daniela@yahoo.com.br 
desenvolvida como alternativa para a sustentabilidade das propriedades e da região (Finamore, 2010). Autores como Ambrosi et al. (2001) afirmam que propriedades rurais familiares, ao diversificarem suas atividades usando ILP, aumentam a rentabilidade e reduzem os riscos de insucesso econômico. Balbinot Jr. et al. (2009) apontam para uma promissora eficiência da ILP, desde que fundamentos básicos sejam atendidos, entre eles o manejo correto da pastagem e a correção de acidez e fertilidade do solo.

Mesmo em ILP, entretanto, a pressão por produção de grãos, principalmente soja, concomitante à produção leiteira pode levar a um estrangulamento desta, devido à restrição alimentar (Bitencourt et al., 2000). Ainda, para Martins et al. (2006), a sazonalidade de oferta alimentar aos animais pode resultar em perdas da qualidade do leite, em especial sobre os componentes como gordura, proteína e sólidos não gordurosos, por serem esses os atributos influenciados pela dieta dos animais (Bueno et al., 2005). Ademais, as propriedades agrícolas, ao elencarem o cultivo de grãos como atividade primária, passam a praticar, normalmente, a atividade leiteira com pouco investimento e baixa especialização, acarretando problemas para toda a cadeia produtiva leiteira (Nero et al., 2009).

A hipótese deste artigo é a de que, entre os vários fatores ligados à eficácia das propriedades familiares na execução da ILP e na qualidade do leite, o uso do solo passa a ter importância fundamental para ambas as explorações: lavoura e pecuária. Assim, se as premissas corretas do uso do solo não forem consideradas em propriedades familiares com ILP, o sistema pode apresentar-se agronomicamente ineficiente, com reflexos em parâmetros de qualidade do leite. Nesse sentido, o presente estudo teve como objetivo investigar o uso do solo em propriedades familiares manejadas sob ILP em bacia hidrográfica com exploração leiteira, bem como avaliar a qualidade do leite (teor de gordura, proteína e sólidos não gordurosos).

\section{MATERIAL E MÉTODOS}

Este estudo foi desenvolvido em bacia hidrográfica $(\mathrm{BH})$, localizada no município de Vila Maria- RS (coordenadas 52 06'54', a $52^{\circ} 03^{\prime} 18^{\prime \prime}$ ' de longitude W e $28^{\circ} 35^{\prime} 06^{\prime \prime}$ ' a 2836'06' de latitude S). De um total de 27 propriedades familiares (PF) instaladas, em 14 PF aplicou-se, no mês de março de 2010, uma enquete abrangendo questões a respeito do uso do solo e de características da atividade leiteira (área total da PF, uso do solo, sistema de pastejo, produção de leite, total de animais, categoria dos animais, qualidade do leite). Com os resultados das enquetes, as $14 \mathrm{PF}$ foram agrupadas em função da similaridade de uso do solo, conforme Tab. 1.

Tabela 1. Agrupamento das PF praticantes de integração lavoura-pecuária da BH em função do destino do cultivo de espécies anuais de inverno (2010) e verão (2010/2011) (colheita de grãos: CG e alimentação animal: AA) e área total de cada grupo de PF

\begin{tabular}{|c|c|c|c|c|c|c|c|c|}
\hline \multirow[t]{3}{*}{ Grupo } & \multicolumn{3}{|c|}{$\begin{array}{l}\text { Destino do cultivo de } \\
\text { espécies anuais de }\end{array}$} & \multirow[t]{2}{*}{$\begin{array}{l}\text { Área } \\
\overline{\mathrm{X}}_{\text {Grupo }}\end{array}$} & \multicolumn{2}{|c|}{$\begin{array}{c}\text { Área } \bar{X}_{\text {Grupo }} \text { destinada } \\
\text { à alimentação } \\
\text { animal }\end{array}$} & \multicolumn{2}{|c|}{$\begin{array}{l}\text { Proporção da área } \\
\bar{X}_{\text {Grupo }} \text { destinada à } \\
\text { alimentação animal }\end{array}$} \\
\hline & \multirow[t]{2}{*}{ Inverno } & \multirow{2}{*}{\multicolumn{2}{|c|}{ Verão }} & & Inverno & Verão & Inverno & Verão \\
\hline & & & & ha & \multicolumn{2}{|c|}{ ha } & \multicolumn{2}{|c|}{$\%$} \\
\hline $1_{n: 3}$ & CG AA & CG & $\mathrm{AA}$ & 42,0 & 14,0 & 10,0 & 33 & 23 \\
\hline $2 n: 8$ & AA & $\mathrm{CG}$ & $\mathrm{AA}$ & 17,3 & 13,7 & 6,7 & 79 & 38 \\
\hline $3_{\mathrm{n}: 3}$ & AA & \multicolumn{2}{|c|}{ AA } & 11,1 & 10,0 & 10,0 & 90 & 90 \\
\hline
\end{tabular}

As PF foram numeradas de acordo com a ordem em que estavam alocadas no território da $\mathrm{BH}$, dessa forma os grupos foram compostos pelas seguintes PF: Grupo 1) PF1, PF25 e PF27; Grupo 2) PF2, PF4, PF12, PF17, PF18, PF23, PF24 e PF26; Grupo 3) PF11, PF13 e PF20; n: número de repetições em cada situação.

De modo geral, as PF se caracterizam pela produção de animais manejados sob pastejo contínuo, mantidos de forma extensiva. Quanto à rotação de cultura, as espécies cultivadas pelas
PF e destinadas à colheita de grãos foram: i) no inverno: trigo, cujo ciclo de cultivo deu-se no período compreendido entre maio e outubro/2010; e ii) no verão: soja, cujo ciclo 
deu-se, em média, de novembro/2010 a abril/2011. Os cultivos destinados à alimentação animal foram: i) no inverno: aveia+azevém, com ciclo de maio a setembro/2010; e ii) no verão: milho, cujo ciclo estendeu-se de outubro/2010 a fevereiro/2011.

Amostras de leite foram coletas entre os meses de maio de 2010 e fevereiro de 2011. Em virtude do ciclo das espécies destinadas à alimentação animal, consideraram-se as coletas realizadas em 15/05/10, 25/05/10 e 31/08/10 como representativas da qualidade do leite no período de inverno, e as coletas realizadas em 06/10/10, 26/11/10, 12/01/11 e 15/02/11 como representativas da qualidade do leite no período de verão.

A coleta se constituiu de uma alíquota de $40 \mathrm{~mL}$ de leite retirada do tanque refrigerador de leite de cada PF, seguindo procedimentos descritos no anexo IV da Instrução Normativa $\mathrm{N}^{\circ} 51$ de 18/09/2002 (Brasil, 2002). Utilizou-se um frasco de polietileno com capacidade para $50 \mathrm{~mL}$, o qual continha um comprimido de bronopol (conservante). Os frascos contendo as amostras de leite foram armazenados em caixa isotérmica com gelo reciclável, a uma temperatura próxima de $4{ }^{\circ} \mathrm{C}$, até chegarem ao laboratório de Serviço de Análises de Rebanhos Leiteiros da Universidade de Passo Fundo (Sarle-UPF). A determinação da composição química (teor de gordura, proteína e sólidos não gordurosos) deuse pela leitura de uma amostra de leite cru. O equipamento utilizado foi um Bentley 2000 (Bentley Instruments ${ }^{\circledR}$ ), que utiliza a tecnologia do infravermelho. Os resultados foram expressos em percentual.

Confrontaram-se as médias dos teores de gordura, proteína e sólidos não gordurosos de cada grupo em cada período (inverno e verão). Também, analisaram-se a qualidade química do leite no período de verão e de inverno em cada grupo e a qualidade do leite de todas as $\mathrm{PF}$ estudadas (n:14) na BH de Vila Maria em cada estação. Para tal, utilizou-se um delineamento inteiramente ao acaso, com diferentes números de repetições, segundo a Tab. 1. As médias foram submetidas à análise de variância e, quando significativas pelo teste $\mathrm{F}(\mathrm{p}<0,05)$, foram comparadas pelo teste Tukey $(\mathrm{p}<0,05)$. O pacote estatístico utilizado foi Assistat (Silva e Azeredo, 2008).

\section{RESULTADOS E DISCUSSÃO}

De maneira geral, o resultado das enquetes aplicadas às $\mathrm{PF}$ da $\mathrm{BH}$ revelou que a maioria das PF $(57,1 \%)$ é menor que 20 ha, 35,7\% apresentam entre 21 e 60 ha e apenas $7,1 \%$ são maiores que 60 ha. Do total das PF, 67\% praticam integração lavoura-pecuária. Percebe-se que a tipificação da $\mathrm{BH}$ quanto ao uso do território é bastante similar ao observado em outras regiões do Brasil (Nero et al., 2009).

O Grupo 1, o qual apresenta área média maior (42 ha), tem como atividade principal o cultivo de grãos, tanto no período de inverno como no período de verão (Tab. 1). Consequentemente, o grupo apresenta baixo uso do solo com pecuária leiteira, 33 e 23\%, para o inverno e verão, respectivamente. A porcentagem da área total cultivada com espécies destinadas à alimentação animal aumentou do Grupo 1 para o Grupo 3, tanto no período de verão quanto no de inverno (Tab. 1). Isso sugere que o Grupo 2 é um exemplo típico da integração lavoura-pecuária, pois, no período de inverno, destina maior porcentagem da área à alimentação animal e, no período de verão, parte das áreas destinadas ao pastejo animal no inverno passa a ser utilizada para semeadura de espécies destinadas à colheita de grãos. O Grupo 3 é o mais especializado na atividade leiteira, pois, em cada estação de cultivo, $90 \%$ da área total são destinados à alimentação animal.

De modo geral, quanto maior a área total da PF, maior é a área cultivada com espécies anuais de verão $\left(r^{2}=0,98^{(\mathrm{p}<0,01)}\right)$ e inverno $\left(r^{2}=0,92^{(\mathrm{p}<0,01)}\right)$ destinadas à colheita de grãos. Isso sugere que a exploração leiteira é preponderante sobre as PF com pequenas áreas, enquanto as PF com áreas maiores tendem a destinar mais área para uso do solo como lavoura de grãos, apesar de manter o sistema de integração lavoura-pecuária. Esse modelo de uso do solo tem consequências sobre o planejamento do rebanho. Observa-se que há um decréscimo na média do total de animais do rebanho e na produção média de litros de leite/vaca/dia do Grupo $1(28,7 ; 14,3)$, Grupo 2 $(25,5 ; 17,1)$ e Grupo $3(14,7 ; 11,7)$. No entanto, apesar do menor número de animais no rebanho, em média, os animais em lactação representam $42,8 \%, 49,4 \%$ e $59,1 \%$ do rebanho total para os Grupos 1, 2 e 3, respectivamente. Isso se deve à 
maior especialidade das PF do Grupo 3 na produção de leite.

A qualidade do leite produzido pelos grupos nos períodos de inverno e verão pode ser observada na Tab. 2. Os grupos de uso do solo não se mostraram determinantes para o teor de gordura, proteína e sólidos não gordurosos do leite durante o período de inverno (Tab. 2). Atribui-se esse resultado ao fato de os grupos cultivarem as mesmas espécies anuais de inverno (aveia preta e azevém) destinadas ao pastejo animal. Segundo Fontaneli e Fontaneli (2000), as gramíneas temperadas dos gêneros Lolium e Avena são forrageiras de excelente qualidade comparadas com as gramíneas tropicais de verão. Já os grupos diferenciaram-se no período de verão (Tab. 2). O leite produzido nas PF que compõem o Grupo 3 apresentou teor de proteína e sólidos não gordurosos superior ao leite produzido pelas PF do Grupo 1, mas não diferiu estatisticamente daquele do Grupo 2. De acordo com Bueno et al. (2005), o teor de gordura do leite apresenta grande influência da dieta do rebanho e decresce em decorrência da inibição da síntese da glândula mamária ou da escassez de precursores lipídicos. Carvalho (2000) aponta diversos aspectos que exercem efeito sobre a composição bromatológica do leite, entre eles: fator racial e seleção genética, estágio de lactação, temperatura ambiente e condições de estresse do animal, perda excessiva de condição corporal, estação do ano, contagem de células somáticas, saúde geral do animal, manifestação de cio, frequência e técnica de ordenha e fatores nutricionais. Para Bauman e Griinari (2003), os fatores nutricionais têm sido considerados como o principal fator que contribui para a variação na constituição do leite. Assim, a razão de os teores dos componentes da qualidade do leite produzido nas PF que compõem o Grupo 3 se apresentarem superiores aos dos Grupos 1 e 2, durante o verão, deve-se parcialmente ao fato de esse grupo cultivar espécies anuais de verão destinadas à alimentação animal em maior porcentagem da área. Nos demais grupos estudados, no período de verão, o principal uso do solo é o cultivo de grãos, como a soja. O uso do solo que prioriza espécies anuais de verão destinadas à colheita de grãos em PF praticantes de bovinocultura de leite também foi constatado por Noro et al. (2006).

Tabela 2. Teores (\%) de gordura, proteína e sólidos não gordurosos presentes no leite, durante os períodos de inverno e verão, em cada grupo de $\mathrm{PF}$ da $\mathrm{BH}$

\begin{tabular}{|c|c|c|c|c|c|c|}
\hline \multirow{3}{*}{ Grupo } & \multicolumn{3}{|c|}{ Período de inverno n:4 } & \multicolumn{3}{|c|}{ Período de verão $n: 3$} \\
\hline & Gordura & Proteína & $\begin{array}{c}\text { Sólidos não } \\
\text { gordurosos }\end{array}$ & Gordura & Proteína & $\begin{array}{l}\text { Sólidos não } \\
\text { gordurosos }\end{array}$ \\
\hline & \multicolumn{6}{|c|}{ o r o r } \\
\hline $1_{\mathrm{n}: 3}$ & $3,75^{\mathrm{ns}}$ & $3,11^{\mathrm{ns}}$ & $8,62^{\mathrm{ns}}$ & $3,34 b$ & $2,94 b$ & $8,37 b$ \\
\hline $2 \mathrm{n}: 8$ & 3,68 & 3,14 & 8,55 & $3,59 \mathrm{ab}$ & $2,98 b$ & $8,33 b$ \\
\hline $3_{n: 3}$ & 3,92 & 3,22 & 8,62 & $3,79 \mathrm{a}$ & $3,20 \mathrm{a}$ & $8,72 \mathrm{a}$ \\
\hline
\end{tabular}

Composição dos grupos: Grupo 1) P1, P25 e P27; Grupo 2) P2, P4, P12, P17, P18, P23, P24 e P26; Grupo 3) P11, P13 e P20; n: número de repetições em cada situação. ns: não significativo pelo teste F. Médias seguidas de mesma letra não diferem pelo teste Tukey $(\mathrm{p}<0,05)$.

Ao se comparar a composição química do leite, em cada estação de cultivo, para cada grupo (Tab. 3), percebe-se que os teores de gordura, proteína e sólidos não gordurosos do leite produzido pelas PF que compõem o Grupo 1 e o Grupo 2 são maiores no período de inverno. Essa constatação indica haver uma variação na qualidade do leite em função da época do ano, o que pode ser associado à restrição alimentar imposta aos animais no período de verão, visto que nessa estação há redução da área cultivada com espécies anuais destinadas à alimentação animal. Já a composição química do leite produzido pelas PF do Grupo 3 não apresentou variações durante as estações do ano. Tal fato pode ser atribuído à constante área destinada à alimentação animal tanto no inverno como no verão. Assim, a melhoria da qualidade do leite é fruto de maiores investimentos, principalmente no que tange à oferta de alimentação animal (Stumpf Jr., 2000; Bueno et al.,2005; Zanela et al., 2006). 
Tabela 3. Teores (\%) de gordura, proteína e sólidos não gordurosos do leite observados em cada grupo de PF da BH durante as estações de inverno e de verão

\begin{tabular}{ccccc}
\multirow{2}{*}{ Grupo } & \multirow{2}{*}{ Estação } & Gordura & Proteína & \multirow{2}{*}{ Sólidos não gordurosos } \\
\cline { 3 - 4 } & Inverno $_{\mathrm{n}: 4}$ & $3,72^{*}$ & $\%$ & $8,12^{*}$ \\
\hline \multirow{2}{*}{$1_{\mathrm{n}: 3}$} & Verão $_{\mathrm{n}: 3}$ & 3,34 & 2,94 & 9,37 \\
& Inverno $_{\mathrm{n}: 4}$ & $3,68^{*}$ & $3,14^{*}$ & $8,55^{*}$ \\
& Verão $_{\mathrm{n}: 3}$ & 3,59 & 2,98 & 8,33 \\
\hline \multirow{2}{*}{$3_{\mathrm{n}: 3}$} & Inverno $_{\mathrm{n}: 4}$ & $3,92^{\mathrm{ns}}$ & $3,22^{\mathrm{ns}}$ & $8,56^{\mathrm{ns}}$ \\
& Verão $_{\mathrm{n}: 3}$ & 3,79 & 3,20 & 8,72 \\
\hline
\end{tabular}

Composição dos grupos: Grupo 1) P1, P25 e P27; Grupo 2) P2, P4, P12, P17, P18, P23, P24 e P26; Grupo 3) P11, P13 e P20; n: número de repetições em cada situação. ns: não significativo pelo teste $\mathrm{F}$ ** Médias diferem estatisticamente entre si pelo teste $\mathrm{T}(\mathrm{p}<0,05)$.

Ao se analisar a qualidade do leite total em cada estação de cultivo, percebe-se que o teor de proteína e sólidos não gordurosos do leite foi afetado pela estação de cultivo $(\mathrm{p}<0,05)$, pois registrou-se teor de proteína $(3,15 \%)$ e de sólidos não gordurosos $(8,57 \%)$ maior na estação de inverno em relação à estação de verão $(3,02 \%$ e $8,42 \%$ para proteína e sólidos não gordurosos, respectivamente), corroborando os resultados de Noro et al. (2006). A variação da composição química pode ser relacionada parcialmente às variações da qualidade dos alimentos, o que confirma os resultados de Martins et al. (2006) e Roma Jr. et al. (2009).

Em resumo, o uso do solo afeta a qualidade do leite, mais intensivamente em PF com maiores áreas totais e que destinam prioritariamente as áreas de suas propriedades ao cultivo de grãos no verão. Tal fato se deve ao planejamento de uso do solo nas propriedades que prioriza a produção de grãos em detrimento da produção leiteira. $\mathrm{O}$ uso do solo em PF com áreas pequenas tende ser mais adequado à produção leiteira, com melhor qualidade de leite e estabilidade desta entre as diferentes épocas do ano. Isso porque há uma adequação do número de animais na área e um reduzido destino para a exploração com grãos, o que as torna PF mais especializadas. O Grupo 2, caracterizado como o grupo em que as PF são típicas na integração lavoura-pecuária, demonstra ser sensível à qualidade sazonal do leite, principalmente no verão, quando ocorre o cultivo de soja em detrimento de cultivo de espécies destinadas à alimentação animal, o que reflete diretamente na qualidade do leite.

\section{CONCLUSÕES}

Nas condições encontradas nas propriedades rurais da bacia hidrográfica estudada, o uso do solo em integração lavoura-pecuária que prioriza o cultivo de grãos em detrimento do pastejo animal influencia de forma negativa os teores de gordura, de proteína e de sólidos não gordurosos do leite, principalmente no período de verão. Assim, o planejamento de uso do solo nessas PF é fundamental, pois evitaria a competição entre a atividade agrícola e a pecuária, bem como os reflexos negativos na qualidade do leite. As PF especializadas na atividade leiteira apresentam melhor qualidade do leite, sendo esta estável durante as estações do ano.

\section{AGRADECIMENTOS}

À Fundação de Amparo à Pesquisa do Estado do Rio Grande do Sul (Edital Procoredes VI Processo: 0905280), pelo auxílio financeiro ao trabalho. Edson C. Bortoluzzi agradece ao $\mathrm{CNPq}$, pela bolsa produtividade em pesquisa nível 2.

\section{REFERÊNCIAS}

ALBUQUERQUE, J.A.; ALMEIDA, J.A.; GATIBONI, L.C.; ELTZ, FL.F. Atividades agrícolas de produção em solos frágeis no Sul do Brasil. In: KLAUBERG FILHO, O. (Ed.). Tópicos em Ciência do Solo. Sociedade Brasileira de Ciência do Solo, 2011. p.367-403.

AMBROSI, I.; SANTOS, H.P. dos; FONTANELI, R.S.; ZOLDAN, S.M. Lucratividade e risco de sistemas de produção de grãos com pastagens, sob plantio direto. Pesqui. Agropecu. Bras., v.36, p.1213-1219, 2001 
ANGHINONI, I.; MORAES, A.; CARVALHO, P.C.F. et al. Benefícios da integração lavourapecuária sobre a fertilidade do solo em sistema plantio direto. In: FONSECA, A.F. da; CAIRES, E.F.; BARTH, G. Fertilidade do solo e nutrição de plantas no sistema plantio direto. AEACG/Inpag: Ponta Grosa, 2011. p.1-30.

BALBINOT JR.; MORAES, A.; VEIGA, M. et al. Integração lavoura-pecuária: intensificação de uso de áreas agrícolas. Cienc. Rural, v.39, p.1925-1933, 2009.

BAUMAN, D.E.; GRIINARI, J.K. Nutritional regulation of milk fat synthesis. Annu. Rev. Nutr., v.23, p.203-227, 2003.

BITENCOURT, D.; PEGORARO, L.M.C.; GOMES, J.F. Sistemas de pecuária de leite: uma visão na região de Clima Temperado. Pelotas: Embrapa Clima Temperado, 2000. 195p.

BRASIL. Ministério da Agricultura, Pecuária e Abastecimento. Instrução Normativa ${ }^{\circ} 51$, de 20 de setembro de 2002. Aprova os Regulamentos Técnicos de produção, identidade e qualidade do leite tipo. Diário Oficial da União, Brasília, 18 de Setembro de 2002. Seção 1. Disponível em: $<$ http://extranet.agricultura.gov.br/sislegisconsulta/consultarLegislacao.do?operacao=visua lizar\&id=8932> . Acessado em: 20 mai. 2009.

BRASIL. IBGE. Censo Agropecuário 2009. Disponível em:

<http://www.ine.gov.mz/censos_dir/

agropecuaria/censoagropecuario.pdf $>$. Acessado em: 18 abr. 2011.

BUENO, V.F.F.; MESQUITA, A.J.; NICOLAU, E.S. et al. Contagem de celular somática: relação com a composição centesimal do leite e período do ano no Estado de Goiás. Cienc. Rural, v.35, p.848-854, 2005.

CARVALHO, M.P. Manipulando a composição de leite: gordura. $1^{\circ}$ Curso on line sobre qualidade do leite. Instituto Fernando Costa: Milkpoint. 2000.

CARVALHO, P.C.F.; ANGHINONI, I.; MORAES, A. et al. O estado da arte em integração lavourapecuária. In: GOTTSCHALL, C.S.; SILVA, J.L.S.; RODRIGUES, N.C. (Org.). Produção animal: mitos, pesquisa e adoção de tecnologia. Canoas, 2005. p.7-44.
FINAMORE, E.B. (Org.). Planejamento estratégico da região da produção: do diagnóstico ao mapa estratégico 2008/2028. Passo Fundo: Universidade de Passo Fundo, 2010. 156p.

FONTANELI, R.S.; FONTANELI, R. Cadeia forrageira para a produção de leite no Rio Grande do Sul. In: FONTANELI, R.S; DÜRR, J.W.; FONTANELI, R. (Ed.) Sistemas de produção de leite. Passo Fundo: Universidade de Passo Fundo, 2000. p.59-85.

MARTINS, P.R.G.; SILVA, C.A.; FISCHER, V. et al. Produção e qualidade do leite na bacia leiteira de Pelotas- RS em diferentes meses do ano. Cienc. Rural, v.36, p.209-214, 2006.

NERO L.A.; VIÇOSA, G.N.; PEREIRA F.E.V. Qualidade microbiológica do leite determinada por características de produção. Cienc. Tecnol. Aliment., v.29, p.386-390, 2009.

NORO, G.; GONZÁLEZ, F.H.D.; CAMPOS, R.; DÜRR, J.W. Fatores ambientais que afetam a produção e a composição do leite em rebanhos assistidos por cooperativas no Rio Grande do Sul. R. Bras. Zootec., v.35, p.1129-1125, 2006.

ROMA Jr., L.C.; MONTOYA, J.F.G.; MARTINS, T.T. et al. Sazonalidade do teor de proteína e outros componentes do leite e sua relação com programa de pagamento por qualidade. Arq. Bras. Med. Vet. Zootec., v.61, p.1411-1418, 2009.

SILVA, F.A.S.; AZEVEDO, C.A.V. Versão do programa computacional Assistat: Assistência Estatística - para sistema operacional Windows. Universidade Federal de Campina Grande, Campus 1. Campina Grande, 2008.

STUMPF JÚNIOR, W. Produção de leite no Rio Grande do Sul: produtividade e competitividade frente ao Mercosul. In: CICLO DE PALESTRAS EM PRODUÇÃO E MANEJO DE BOVINOS, 2000. Anais... Canoas: Ulbra, 2000. p.19-30.

ZANELA, M.B.; FISCHER, V.; RIBEIRO, M.E.R. et al. Qualidade do leite em sistemas de produção na região Sul do Rio Grande do Sul. Pesqui. Agropecu. Bras., v.41, p.153-159, 2006. 